\title{
Tissue-Engineered Heart Valve with a Tubular Leaflet Design for Minimally Invasive Transcatheter Implantation
}

\author{
Ricardo Moreira, MSc, Thaddaeus Velz, MSc, ${ }^{1}$ Nuno Alves, MSc, ${ }^{1}$ Valentine N. Gesche, Dipl.-Ing. (Univ.), ${ }^{2}$ \\ Axel Malischewski, ${ }^{1}$ Thomas Schmitz-Rode, MD, ${ }^{1}$ Julia Frese, Dipl-Ing. (FH), \\ Stefan Jockenhoevel, MD, ${ }^{1,2}$ and Petra Mela, $\mathrm{PhD}^{1}$
}

Transcatheter aortic valve implantation of (nonviable) bioprosthetic valves has been proven a valid alternative to conventional surgical implantation in patients at high or prohibitive mortality risk. In this study we present the in vitro proof-of-principle of a newly developed tissue-engineered heart valve for minimally invasive implantation, with the ultimate aim of adding the unique advantages of a living tissue with regeneration capabilities to the continuously developing transcatheter technologies. The tube-in-stent is a fibrin-based tissueengineered valve with a tubular leaflet design. It consists of a tubular construct sewn into a self-expandable nitinol stent at three commissural attachment points and along a circumferential line so that it forms three coaptating leaflets by collapsing under diastolic back pressure. The tubular constructs were molded with fibrin and human umbilical vein cells. After 3 weeks of conditioning in a bioreactor, the valves were fully functional with unobstructed opening (systolic phase) and complete closure (diastolic phase). Tissue analysis showed a homogeneous cell distribution throughout the valve's thickness and deposition of collagen types I and III oriented along the longitudinal direction. Immunohistochemical staining against CD31 and scanning electron microscopy revealed a confluent endothelial cell layer on the surface of the valves. After harvesting, the valves underwent crimping for $20 \mathrm{~min}$ to simulate the catheter-based delivery. This procedure did not affect the valvular functionality in terms of orifice area during systole and complete closure during diastole. No influence on the extracellular matrix organization, as assessed by immunohistochemistry, nor on the mechanical properties was observed. These results show the potential of combining tissue engineering and minimally invasive implantation technology to obtain a living heart valve with a simple and robust tubular design for transcatheter delivery. The effect of the in vivo remodeling on the functionality of the tube-in-stent valve remains to be tested.

\section{Introduction}

$\mathbf{V}$ ALVULAR HEART DISEASE is a growing socioeconomic burden worldwide. ${ }^{1}$ Commercially available valve replacements, although lifesaving, still suffer from major limitations such as the need for a life-long anticoagulation therapy in the case of mechanical prostheses, ${ }^{2,3}$ the degeneration and, therefore, limited durability of the biological heart valves, ${ }^{2,3}$ and the limited availability of homografts. ${ }^{4}$

Tissue-engineered heart valves (TEHVs) have the potential to outperform the available valve substitutes with their capability to grow and remodel. Recently the feasibility of combining heart valve tissue engineering, traditionally intended for open-heart surgical procedures, with minimally invasive implantation methods has been shown. ${ }^{5}$ This opened up the possibility of treating with TEHVs the whole spectrum of clinical cases, including patients who are not considered candidates for standard surgical replacement. ${ }^{6,7}$ Historically, TEHVs have been designed to mimic the shape of the native valve in the attempt to recreate the natural hemodynamics. ${ }^{8-16}$ This implies to the fabrication of leaflets to ensure the unidirectional blood flow. However, it is the inadequate leaflets' functionality that ultimately determined the failure of TEHVs in preclinical studies, independently whether a conventional $^{9,17-20}$ or a minimally invasive implantation was performed. ${ }^{5,21,22}$ A generally proposed failure mechanism is the cell-mediated tissue contraction which results in the shortening of the leaflets in the radial direction and, as a consequence, in insufficient coaptation. This process has been reported to occur also during the in vitro tissue conditioning so that (mild-moderate) valve regurgitation was already present in the valves right after delivery. ${ }^{21}$

\footnotetext{
${ }^{1}$ Department of Tissue Engineering and Textile Implants, AME-Institute of Applied Medical Engineering, Helmholtz Institute, RWTH Aachen University, Aachen, Germany.

${ }^{2}$ Institut für Textiltechnik, RWTH Aachen University, Aachen, Germany.
} 
Recently, we proposed an alternative valve design that performs the valve function without mimicking its geometry, ${ }^{23}$ with the ultimate goal of overcoming the leafletassociated limitations. Instead of reproducing the complex shape of the native leaflets, a simple tissue-engineered tubular construct is sutured orthotopically in the aortic or pulmonary root at three distinct sinotubular commissural points, and along a circumferential line at the annulus level, without any rigid support or sewing ring, according to the so-called single point attached commissures (SPACs) technique proposed by Goetz and colleagues. ${ }^{24}$ The tubular construct collapses inwardly under diastolic back pressure, closing the valvular conduit.

In the present article we show the feasibility of combining the tubular leaflet design with a transcatheter valve implantation technique for the realization of a new TEHV to be implanted by minimally invasive delivery. What we refer to as the tube-in-stent, consists of a tissue-engineered tubular construct sewn into a self-expandable nitinol stent by SPACs technique. We produced textile-reinforced fibrin-based tubular constructs incorporating cells from the human umbilical cord vein. After 7 days of static cultivation, the constructs were mounted into nitinol stents, cultivated under dynamic conditions for 7 days, endothelialized with human umbilical vein endothelial cells, and dynamically cultivated for 7 more days. After harvesting, the valves underwent simulated implantation by being crimped, kept in the crimped configuration for $20 \mathrm{~min}$ (estimated time to perform the implantation), and deployed to their original size. Tissue analysis included conventional histology, immunohistochemistry, and scanning electron microscopy (SEM). Collagen content was assessed by hydroxyproline assay and mechanical properties were evaluated by burst strength measurements. All tests were performed on uncrimped and crimped valves to evaluate the influence of the delivery procedure. The valvular functionality was evaluated under in vitro conditions before and after crimping by determining the orifice area during systole and confirming complete closure during diastole.

\section{Materials and Methods}

\section{Mesh production}

The tubular textile mesh was produced at the Institut für Textiltechnik (RWTH Aachen University, Aachen, Germany) on a custom-made double Raschel warp knitting machine, type DR 16 EEC/EAC (Karl Mayer GmbH) using medical grade polyethylene terephthalate (PET) multifilament fibers. For the production, a tüll-filet pattern, a needle gauge of E30 (i.e., 30 needles per inch), and a course density of 15 loops/cm were chosen. Fifty-two PET yarns were processed into a tubular structure which was thermostabilized at $200^{\circ} \mathrm{C}$ for $8 \mathrm{~min}$ before use.

\section{Cell isolation and culture}

Autologous cells (endothelial cells, and a mixed population of smooth muscle cells (SMCs)/fibroblasts) were isolated from veins of human umbilical cords kindly provided by the Department of Gynecology at the University Hospital Aachen in accordance with the human subjects approval of the ethics committee (votum of the local ethics committee: \#EK 2067). The vein was washed with phosphate buffered saline (PBS;
Gibco) before removing endothelial cells by using $1 \mathrm{mg} / \mathrm{mL}$ collagenase (Sigma). Endothelial cells were seeded on $2 \%$ gelatin-precoated tissue culture flasks and incubated with Endothelial Cell Basal Medium (EBM-2; Lonza) supplemented with the EGM-2 kit supplements $(0.1 \%$ insulin, $0.1 \%$ gentamicin, $0.1 \%$ ascorbic acid, $0.4 \%$ human fibroblast growth factor, $2 \%$ fetal bovine serum (FBS), $0.1 \%$ endothelial growth factor, $0.04 \%$ hydrocortisone, $0.1 \%$ epidermal growth factor, $0.1 \%$ heparin; Lonza), $10 \%$ FBS (Gibco), and $1 \%$ antibiotic/antimycotic solution (penicillin-streptomycinamphotericin B; Gibco). For isolation of the mixed population of SMCs/fibroblasts, the digested vein was minced into $1-\mathrm{mm}$ rings and then bathed in the primary cell culture media Dulbecco's modified Eagle's medium (DMEM; Gibco) supplemented with $10 \%$ FBS (Gibco) and 1\% antibiotic/antimycotic solution (Gibco). To obtain a sufficient number, the cells were serially passaged four to five times using $0.25 \%$ trypsin/0.02\% EDTA solution (Gibco) and cultured in 5\% $\mathrm{CO}_{2}$ and $95 \%$ humidity at $37^{\circ} \mathrm{C}$. Before valve molding, the $\mathrm{SMC} /$ fibroblasts phenotype was verified by the presence of alpha-smooth muscle actin (alpha-SMA)-positive cells and total absence of expression of von Willebrand factor (vWf). Before endothelialization, endothelial cells phenotype was verified by positive immunofluorescence staining for vWf.

\section{Casting of fibrin gel}

Human fibrinogen (Calbiochem) was dissolved in purified water (Milli-Q ${ }^{\mathrm{TM}}$; Millipore) and dialyzed with a cut-off membrane (Novodirect) of 6000-8000 MW overnight against tris-buffered saline (TBS). After sterile filtration, the fibrinogen concentration was determined by measuring the absorbance at $280 \mathrm{~nm}$ with a spectrophotometer (Spectronic GenesysTM 6; Thermo Fisher Scientific GmbH). The final concentration was adjusted to $10 \mathrm{mg} / \mathrm{mL}$ with sterile TBS. The fibrin gel components of the valve $(6.0 \mathrm{~mL}$ in total) consisted of $3.0 \mathrm{~mL}$ of fibrinogen solution $(10 \mathrm{mg} / \mathrm{mL})$, $1.2 \mathrm{~mL}$ of TBS containing $60 \times 10^{6}$ human umbilical vein SMCs/fibroblasts, and $0.9 \mathrm{~mL} 50 \mathrm{mM} \mathrm{CaCl} 2$ (Sigma) in TBS. Fibrin polymerization was initialized by adding $0.9 \mathrm{~mL}$ of thrombin solution $(40 \mathrm{U} / \mathrm{mL}$; Sigma).

\section{The tube-in-stent concept}

The valve consists of a tissue-engineered tubular construct sewn into a stent at three single attachment points and along a circumferential line according to the SPAC technique $^{24}$ as schematically shown in Figure 1. Under these constraints, the tubular construct collapses inwardly upon diastolic back pressure, closing the vascular conduit. The valve can be crimped and implanted with catheter-based minimally invasive technologies.

For the realization of the valves in this study, we chose fibrin as cell carrier and a PET warp knitted mesh as coscaffold. The cell-laden, textile-reinforced, fibrin-based tubular construct was realized by molding technique. We used a self-expandable laser-cut nitinol stent (outer diameter 22 mm; Admedes Schuessler GmbH).

\section{Tube-in-stent fabrication}

To be able to place the construct in a bioreactor for static constrained conditioning, the warp knitted tubular mesh was 

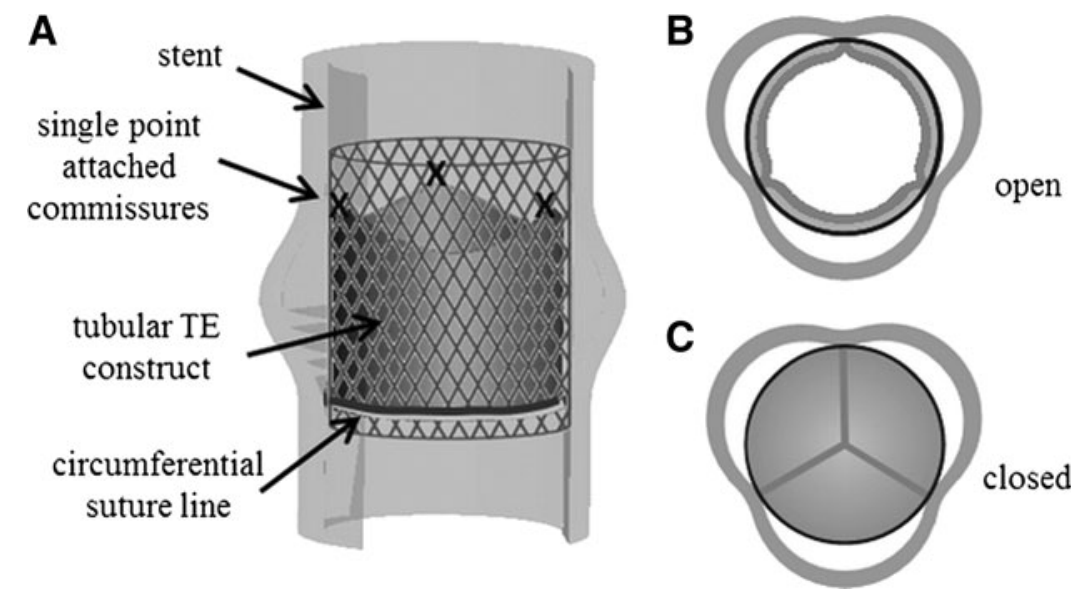

FIG. 1. Concept of the tube-in-stent valve. (A) Tube-in-stent valve placed in the aortic or pulmonary position in $(\mathbf{B})$ open (systolic) and (C) closed (diastolic) configuration. TE, tissue engineered. partially embedded in silicone connectors (Elastosil ${ }^{\circledR}$; Wacker Chemie AG) at both ends (Fig. 2A, B). The mold for the tubular construct consisted of two outer shells and an inner cylinder (Fig. 2A). The mesh was placed onto the cylindrical inner part and after assembling the outer shells, the fibrin gelforming components (including the cells) were injected through a lateral hole in one of the shells. After $45 \mathrm{~min}$, the fibrin polymerization had occurred and the fibrin-based textilereinforced tubular construct was released carefully from the mold, mounted on a polymethylmethacrylate (PMMA) holder (Fig. 2B) and cultivated in longitudinally constrained static conditions for 7 days. After releasing the construct from the silicone connectors, it was sewn into the stent with polybutester sutures (Prolene 6-0; Vascufil ${ }^{\circledR}$ ) first at the commissures and then the annulus (Fig. 2C, D). The tube-in-stent was

placed into a silicone tube featuring the sinuses of Valsalva (Fig. 2E) obtained by molding as previously described. ${ }^{23}$ All mold parts (i.e., to produce the tubular constructs, the silicone connectors, and the silicone tube) were designed with the 3D CAD software Pro/Engineer (Wildfire 5.0; Parametric Technology Cooperation) and produced by rapid prototyping technology (Eden 350v; Object). All parts involved in the fabrication of the tubular construct were sterilized by autoclaving $\left(121^{\circ} \mathrm{C}\right)$. The stent was sterilized with ethanol $70 \%$ (Merck) and rinsed with sterile purified water.

\section{Bioreactor system and operation}

The tube-in-stent valves were cultivated statically for 7 days and dynamically for 14 days at $37^{\circ} \mathrm{C}, 5 \% \mathrm{CO}_{2}$, and
FIG. 2. Fabrication of tube-in-stent valve. (A) Mold components and tubular mesh with silicone connectors; (B) tubular construct placed in a polymethylmethacrylate (PMMA) holder for static cultivation; (C) tube-in-stent seen from the vascular, (D) ventricular and (E) longitudinal side after insertion into a silicone conduit featuring the sinuses of Valsalva.
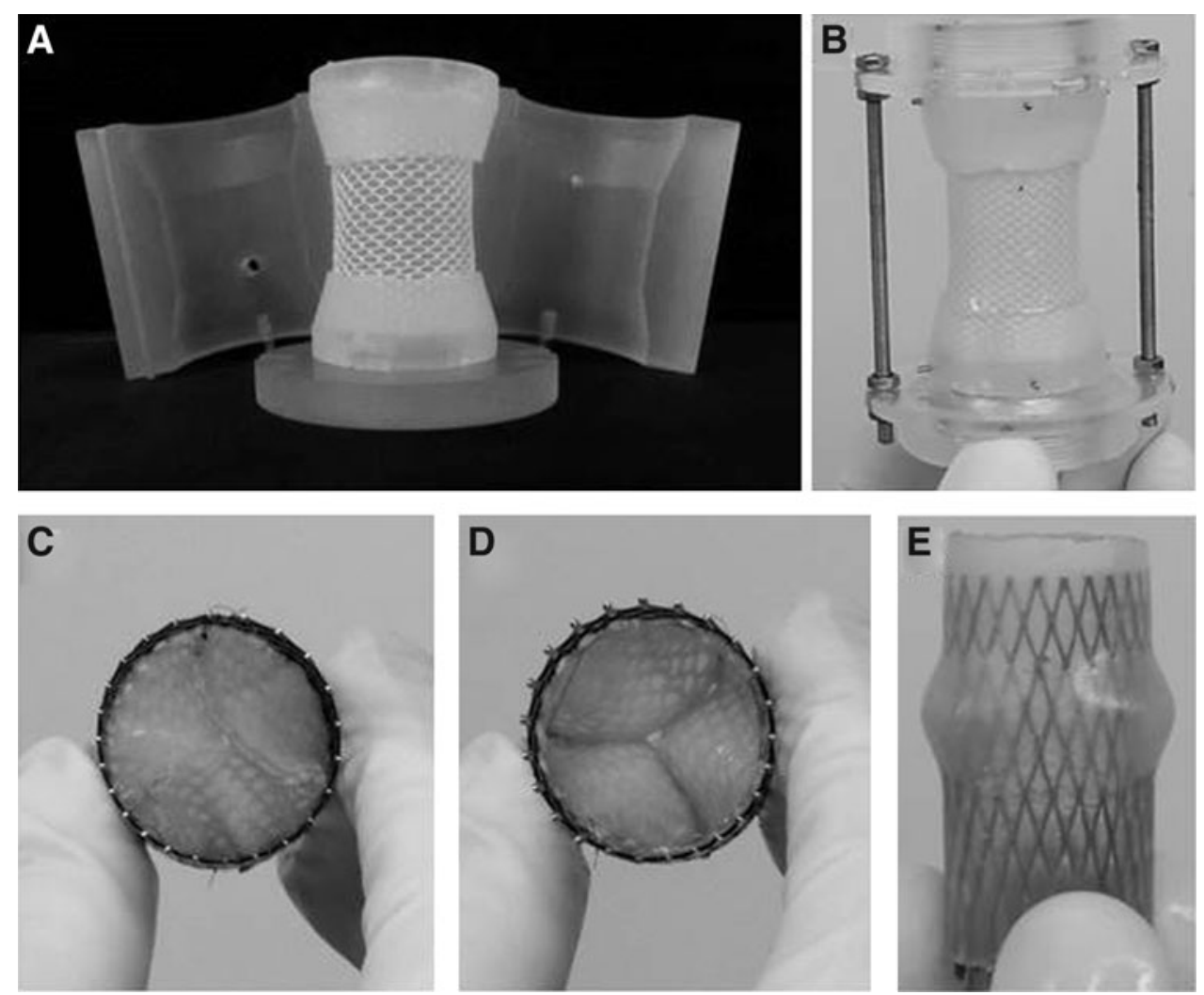
$21 \% \mathrm{O}_{2}$ in a custom-made bioreactor consisting of two PMMA chambers and a linear magnetic actuator, as described previously. ${ }^{23}$ Briefly, the lower chamber functioned as a ventricle pump connected with an upper chamber where the tube-in-stent valve is placed. The magnetic actuator displaces stroke volumes trough the valve. During dynamic stimulation (from day 7 to 21 ), the frequency ranged from 20 to $35 \mathrm{bpm}$ increased in steps of $5 \mathrm{bpm}$ every 3-4 days. The gas exchange was guaranteed by an external peristaltic pump (MCP Process; Ismatec), recirculating the medium through gas-permeable silicone tubes and by a gas filter placed on the top of the bioreactor. During the first 14 days, the valves were cultured in low glucose medium DMEM supplemented with 10\% FBS (Gibco), 1\% antibiotic/antimycotic solution (Gibco), 1.0 mM L-ascorbic acid 2-phospate (Sigma), and $1,6 \mu \mathrm{L} / \mathrm{mL}$ tranexamic acid (CyklokapronInjection solution $1000 \mathrm{mg} / \mathrm{mL}$; Pfizer Pharma $\mathrm{GmbH}$ ). The culture medium was replaced every 3-4 days. At day 14 , the valves were transferred to a customized, rotating cell-seeding chamber for endothelialization. The custom-made chamber was filled with $30 \mathrm{~mL}$ EBM-2 (Lonza) containing $30 \times 10^{6}$ endothelial cells. The chamber was rotated along its axis at $1 \mathrm{rpm}$ for $20 \mathrm{sec}$ and kept still for the following $200 \mathrm{sec}$ to facilitate cell attachment. The cycle was repeated for $4 \mathrm{~h}$. The gas exchange was guaranteed by an external gas filter. After endothelialization, the valves were transferred back to the bioreactor and conditioned dynamically for the following 7 days in EBM-2 (Lonza) supplemented with 10\% FBS (Gibco), 1\% antibiotic/antimycotic solution (Gibco), $1.0 \mathrm{mM}$ L-ascorbic acid 2-phospate (Sigma), $1.6 \mu \mathrm{L} / \mathrm{mL}$ tranexamic acid (Pfizer Pharma GmbH), and EGM-2 kit supplements (Lonza). During the total 21 days of cultivation, the culture conditions were monitored every 2 days by measuring glucose and lactate concentration, $p \mathrm{O}_{2}, p \mathrm{CO}_{2}$, and $\mathrm{pH}$ by means of an automatic blood-gas analyzer (Radiometer ABL 800 Flex; Radiometer Medical A/S). All PMMA components were sterilized by low-temperature hydrogen peroxide gas plasma (STERRAD 100S Sterilization System, Ethicon GmbH) at least 4 days before use. All other components were sterilized by autoclaving $\left(121^{\circ} \mathrm{C}\right)$.

\section{Simulated delivery}

After cultivation, the diameter of the tube-in-stent valves $(n=5)$ was decreased from $22 \mathrm{~mm}$ to $8 \mathrm{~mm}$ (Fig. 3), using a commercial crimping device (MSI Crimping HV200). The valves were left in the crimped configuration for $20 \mathrm{~min}$, representing the time to perform the implantation before being deployed to their original size. Controls $(n=5)$ were treated with the same conditioning protocol, but did not undergo the crimping procedure. The functionality of the valves was as- sessed in terms of orifice area in the open position (systole) before and after crimping. Videos of opening (systole) and closing (diastole) cycles were recorded with a high-speed camera (240 frames per second; Exilim EX-ZR100; Casio Europe). The orifice area of the valves was determined by analysis of frames with the freeware ImageJ (National Institutes of Health).

\section{Evaluation of mean pressure gradient and regurgitation}

The tube-in-stent valves $(n=3)$ were tested in a homemade flow-loop system at aortic conditions (cardiac output of $5 \mathrm{~L} / \mathrm{min}$ (pulsatile flow); $100 \mathrm{mmHg}$ mean aortic pressure $(80-120 \mathrm{mmHg}$ ) and $70 \mathrm{bpm}$ frequency) to determine the mean pressure gradients and the regurgitation. The valves were positioned in a silicone tube featuring the sinuses of Valsalva produced by molding ${ }^{23}$ creating a tight fitting between the stent and the silicone construct. The pressures were measured by pressure transducers positioned immediately upstream and downstream the valve (CODAN pvd Critical Care $\mathrm{GmbH}$ ) and the instantaneous flows were measured by a flow meter (sonoTT, em-tec $\mathrm{GmbH}$ ) positioned downstream the valve. Pressure and flow values were recorded by a LabVIEW ${ }^{\mathrm{TM}}$ application (National Instruments) and averaged over five cycles.

\section{Bright field microscopy}

Tissue samples were rinsed in PBS, fixed in Carnoy's fixative, and embedded in paraffin for subsequent histological analysis. Carnoy's fixed, paraffin-embedded native human aortic and tissue-engineered valves were sectioned at $3 \mu \mathrm{m}$ thickness longitudinally and stained by standard $\mathrm{He}-$ matoxylin and Eosin (H\&E) protocol for analysis of general tissue morphology and Gomori's Trichrome protocols for the analysis of tissue development. Human aortic valve samples were kindly provided by the Institute of Pathology at the University Hospital Aachen in accordance with the regulations of the Local Ethics. Sections were analyzed by routine bright field microscopy (AxioImager D1; Carl Zeiss $\mathrm{GmbH}$ ) and images were acquired using a digital color camera (AxioCam MRc; Carl Zeiss GmbH).

\section{Immunohistochemistry}

Nonspecific sites on Carnoy's-fixed, paraffin-embedded sections from native human aortic and tissue-engineered valves were blocked and the cells were permeabilized with $5 \%$ normal goat serum (NGS; Dako) in $0.1 \%$ Triton-PBS. Sections were incubated for $1 \mathrm{~h}$ at $37^{\circ} \mathrm{C}$ with the following primary antibodies: 1:1000 mouse anti-alpha-SMA (A 2547;
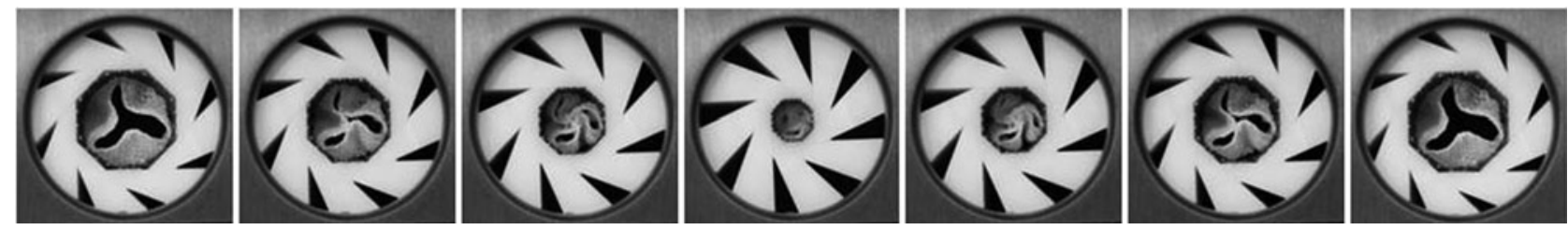

FIG. 3. Crimping of the tube-in-stent valve. The diameter was decreased from $22 \mathrm{~mm}$ to $8 \mathrm{~mm}$ and the valves were kept in the crimped state for $20 \mathrm{~min}$ before letting it return to the original size. 
Sigma); 1:200 rabbit anti-type collagen I (R 1038; Acris); 1:25 rabbit anti-type collagen III ( $\mathrm{R}$ 1040; Acris); 1:200 rabbit anti-elastin (20R-ER003; Fitzgerald), 1:50 mouse anti-fibronectin (F6140-.2ML; Sigma); 1:200 mouse antichondroitin sulfate (C8035-.2ML; Sigma), and 1:25 mouse antiCD31 (P8590; Sigma-Aldrich). The sections were incubated for $1 \mathrm{~h}$ at $37^{\circ} \mathrm{C}$ with either rhodamine or fluorescein-conjugated secondary antibodies: 1:400 mouse (A 11005; Molecular Probes) for alpha-SMA, fibronectin, chondroitin sulfate, and CD31; 1:400 rabbit (A11008; Molecular Probes) for collagen type I and elastin, and 1:300 rabbit immunoglobulins/biotinylated (E 0432; Dako) for collagen type III. Collagen type III signal was amplified by an additional incubation with 1:1000 streptavidin/TRITC (RA 021; Acris). A native human aortic valve served as a positive control. As negative controls, samples were incubated in diluent and the second antibody only. Tissue sections were counterstained with DAPI nucleic acid stain (Molecular Probes). Samples were observed with a microscope equipped for epi-illumination (AxioObserver Z1; Carl Zeiss $\mathrm{GmbH}$ ). Images were acquired using a digital camera (AxioCam MRm; Carl Zeiss GmbH). Cellular alignment of SMCs/fibroblasts was evaluated by analyzing immunohistological images of samples stained against alpha-SMA with the freeware ImageJ (National Institutes of Health). The longitudinal axis of the samples was set as preferred orientation $\left(0^{\circ}\right)$. The software evaluates the range of angles (dispersion) corresponding to \pm the standard deviation, which is the range of values where $68 \%$ of the cells are included.

\section{Scanning electron microscopy}

Tissue-engineered samples were fixed in 3\% glutaraldehyde for at least $24 \mathrm{~h}$, rinsed with sodium phosphate buffer $(0.2 \mathrm{M}, \mathrm{pH} 7.39$, Merk) and dehydrated consecutively in $30 \%, 50 \%, 70 \%$, and $90 \%$ acetone and then three times in $100 \%$ acetone for $10 \mathrm{~min}$. The samples were critical-pointdried in $\mathrm{CO}_{2}$, and sputter coated (Leica EM SC D500) with a $20 \mathrm{~nm}$ gold-palladium layer. Samples were analyzed using a scanning electron microscope (ESEM XL 30 FEG, FEI, Philips) with accelerating voltage of $10 \mathrm{kV}$.

\section{Collagen content quantification (hydroxyproline assay)}

The hydroxyproline content of tissue-engineered samples $(n=3$, from each valve), dried under vacuum overnight, was determined as described by Reddy and Enwemeka. ${ }^{25}$ A standard curve was generated using known amounts of trans-4hydroxy-L-proline (Sigma). Native human aortic valve tissue samples served as positive controls $(n=3)$.

\section{Burst strength measurements}

Burst strength values were determined with a custommade burst strength chamber equipped with a pressure sensor (Jumo Midas pressure transmitter; JUMO GmbH \& Co. KG) and a peristaltic pump (IPC Ismatec; IDEX Health $\&$ Science $\mathrm{GmbH})$. Samples $(n=3$, from each valve) of $1 \mathrm{~cm}^{2}$ area were placed into the burst chamber and exposed to increasing pressure by pumping water until the structural failure of the sample occurred. This point was clearly detectable by a sudden drop in pressure. The highest pressure measured before failure was recorded as the burst strength value with a LabVIEW ${ }^{\mathrm{TM}}$ program (National Instruments).

\section{Statistical analysis}

Statistical significance of differences between groups of valves differently treated was determined by using the Student's t test (GraphPad Prims 6; GraphPad Software, Inc.). Differences were considered to be statistically significant at $p<0.05$. All quantitative results are presented as means \pm standard deviations.

\section{Results}

\section{Valve functionality}

Valve functionality of the tube-in-stent valve is shown in Figure 4, before and after the crimping procedure. Macroscopically, the simulated delivery procedure did not damage the valves and did not affect their performance. The valves showed a complete opening without flow restriction during the systolic phase and complete closure during diastole. The orifice area during systole was $1.70 \pm 0.09 \mathrm{~cm}^{2}$ and $1.75 \pm 0.07 \mathrm{~cm}^{2}$, before and after crimping, respectively $(p>0.05)$.

\section{Mean pressure gradient and regurgitation}

Mean pressure gradients of the valves under aortic conditions as measured in the flow-loop system were $7.3 \pm 1.5 \mathrm{mmHg}$ and $6.8 \pm 1.7 \mathrm{mmHg}$ before and after crimping. Regurgitation
FIG. 4. Still frames of opening and closing cycles of a tube-in-stent valve, before (upper panel) and after crimping (lower panel).

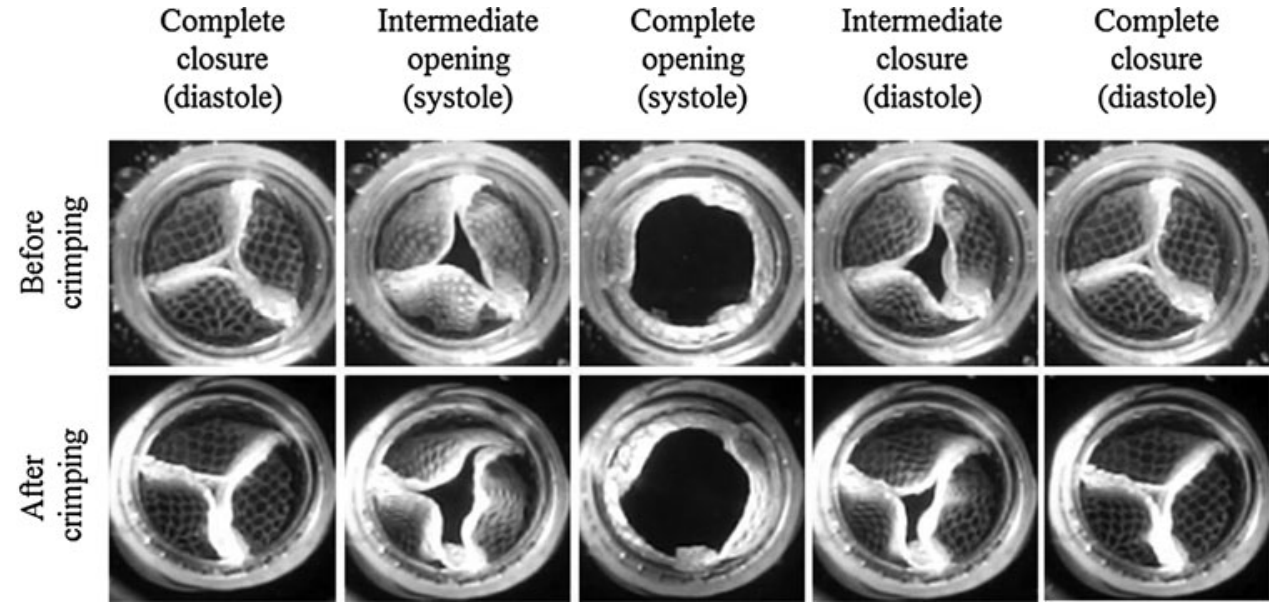


was $15.1 \% \pm 2.5 \%$ and $15.3 \% \pm 3.6 \%$ before and after crimping, respectively $(p>0.05)$.

\section{Tissue analysis}

Tissue formation of tissue-engineered crimped and uncrimped valves was evaluated by conventional H\&E stain- ing and immunohistochemistry (Fig. 5). Independently of the state, H\&E staining showed homogeneous cell distribution throughout the valve's thickness (Fig. 5AA, AC). Gomori's Trichrome staining showed the presence of collagen for uncrimped and crimped valves (Fig. 5AB, AD). Immunohistochemical staining showed the presence of longitudinally aligned alpha-SMA (Fig. 5A, G). Sixty-eight

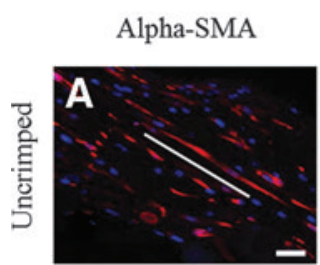

Collagen I
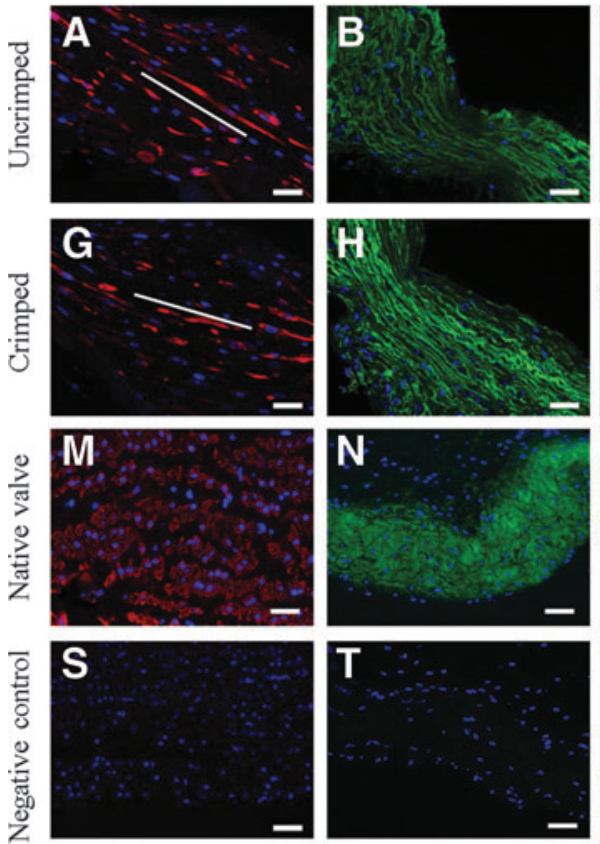

Collagen III
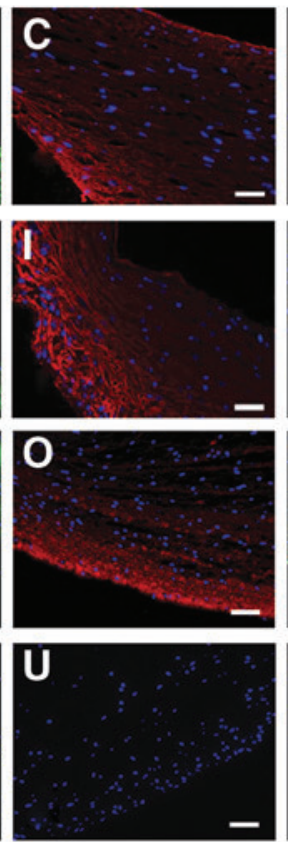

Elastin
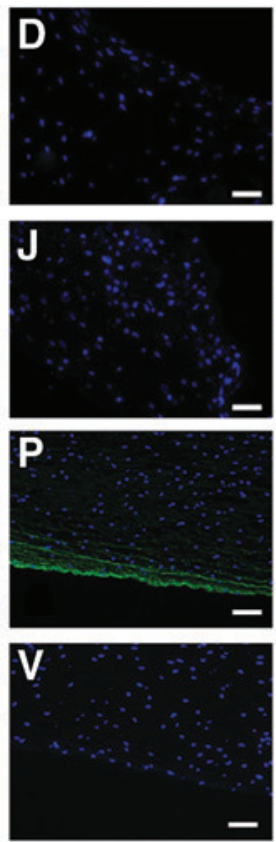

Fibronectin
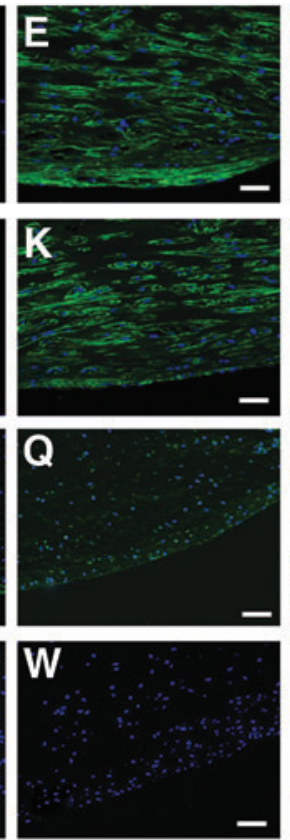

Chondroitin sulphate
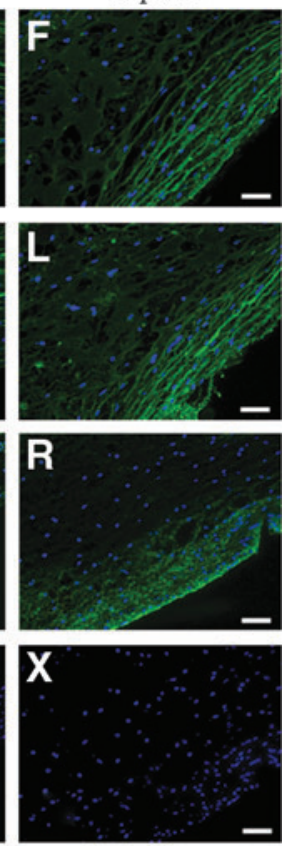
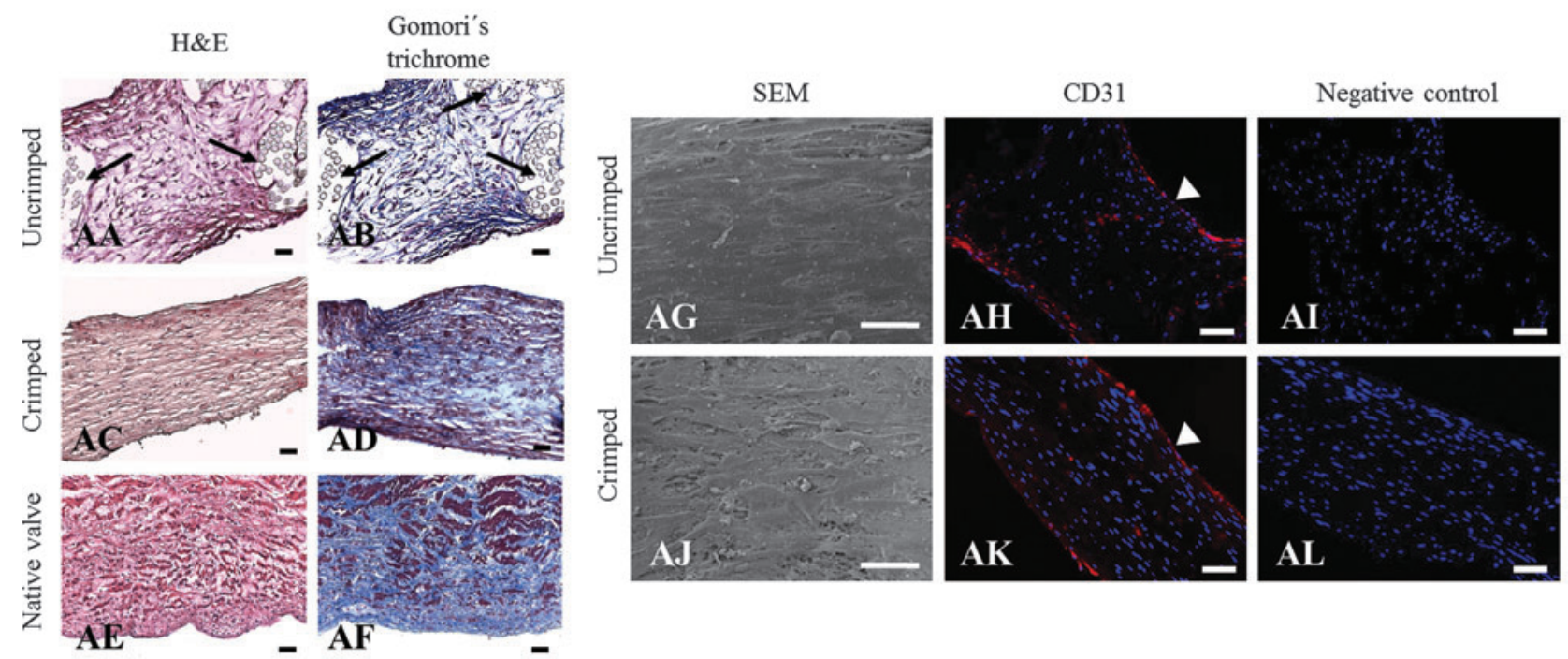

FIG. 5. Tissue analysis by conventional hematoxylin and eosin (H\&E) (AA and AC) and Gomori's Trichrome stainings (AB and AD) and immunohistochemistry of tissue-engineered uncrimped and crimped valves. Immunohistochemical staining against alpha-smooth muscle actin (alpha-SMA) (A, G, and M), collagen type I (B, H, and N), collagen type III (C, $\mathbf{I}$, and $\mathbf{O}$ ), elastin (D, J, and $\mathbf{P})$, fibronectin $(\mathbf{E}, \mathbf{K}$, and $\mathbf{Q})$, and chondroitin sulfate (F, $\mathbf{L}$, and $\mathbf{R})$. A human aortic valve was used as a positive control (M-R, AE, and AF). Endothelium analysis by SEM (AG and AJ, inner surface) and immunohistochemical staining against CD31 (AH and $\mathbf{A K})$ for uncrimped and crimped valves. White lines (A and $\mathbf{G})$ indicate the reference for the cell alignment measurement. White arrows (AH and AK) indicate the inner surface of the valve. Black arrows (AA and $\mathbf{A B})$ indicate the textile mesh. Negative controls (S-X, AI, and $\mathbf{A L})$ for all markers reacted in the absence of the primary antibody showed undetectable levels of staining. Scale bars: $50 \mu \mathrm{m}$. Color images available online at www.liebertpub.com/tec 


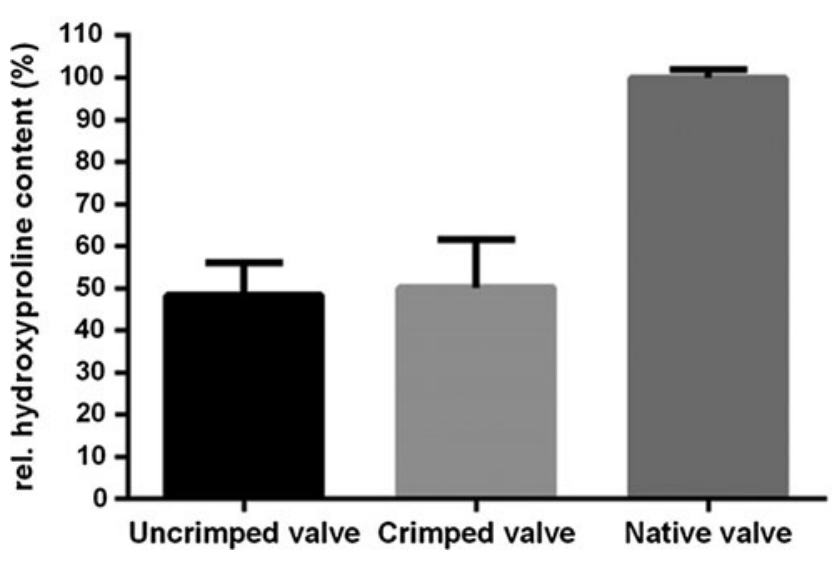

FIG. 6. Hydroxyproline content of uncrimped and crimped valves relative to native human aortic valve.

percent of cells expressing alpha SMA were aligned with a dispersion of $11 \pm 2^{\circ}$ and $13 \pm 1^{\circ}$ from the longitudinal axis for uncrimped and crimped valves, respectively. No significant differences were found in the cell alignment between the two groups. There was a pronounced deposition of collagen types I and III orientated along the longitudinal direction (Fig. 5B, C, H, I). Elastin was not detected. Fibronectin (Fig. 5E, K) and chondroitin sulfate, a sulfated glycosaminoglycan (Fig. 5F, L) were found in the valves for both uncrimped and crimped states. Immunohistochemical staining against CD31 showed the presence of a continuous endothelium in both inner and outer surfaces for uncrimped and crimped valves (Fig. 5AH, AK). Surface morphology was verified by SEM analysis, demonstrating a confluent and orientated cell layer in the uncrimped valves as shown for the inner surface in Figure 5AG (representative of the whole surface). Partial disruption of the endothelial cell layer after crimping could not be excluded in crimped valves (Fig. 5AJ, inner surface).

\section{Collagen content}

The collagen content of uncrimped and crimped valves is shown in Figure 6 expressed as a percentage of the native human aortic valve (considered as 100\%). Uncrimped and crimped valves reached $48.4 \% \pm 7.7 \%$ and $50.1 \% \pm 11.4 \%$, respectively. The crimping procedure did not change the collagen content significantly.

\section{Burst strength}

The textile reinforcement of plain fibrin resulted in an increased burst pressure $(146.1 \pm 46.0 \mathrm{mmHg})$ whereas plain fibrin burst at $44.0 \pm 18.5 \mathrm{mmHg}$. The cultivation protocol resulted in an increase of burst strength to $321.1 \pm 30.9 \mathrm{mmHg}$. The crimping procedure did not alter the value significantly (334.7 $\pm 34.3 \mathrm{mmHg})$.

\section{Discussion}

Minimally invasive transcatheter aortic valve implantation (TAVI) techniques have been developed and evaluated as an alternative to classical surgical procedures for patients with severe aortic stenosis, who are considered inoperable or at high mortality risk. ${ }^{6,7,26} \mathrm{~A}$ randomized trial has indeed confirmed the superiority of the treatment for the first class of patients and the noninferiority for the latter one. ${ }^{26-28}$ The procedure is normally performed either through puncture of the left ventricular apex (transapical TAVI) or percutaneously through the femoral artery (transfemoral TAVI). ${ }^{26}$ The introduction of catheter-based techniques has significantly widened the spectrum of treatment possibilities the surgeons have at their disposal, including the vale-in-valve TAVI in case of dysfunction of a prostheses previously surgically implanted. ${ }^{29}$

The concept of TAVI has also been applied to TEHVs showing the potential of combining a living valve capable of growing and remodeling with a minimally invasive implantation technique. The only reported design so far consists of a classically biomimetic shaped trileaflet tissueengineered valve continuous to the vascular wall integrated into a self-expandable nitinol stent, either as living tissue, ${ }^{5}$ decellularized and reseeded in vitro ${ }^{30}$ or decellularized for in vivo recellularization. ${ }^{21}$ This represents a remarkable step in the development of TEHVs. These valves, however, showed the same issues as the TEHVs conceived for conventional surgical replacement. In fact, the main problem associated with TEHVs is the cell-mediated tissue retraction altering the geometry of the leaflets and, consequently, their functionality. This has now been consistently shown in in vitro and in vivo studies. As a consequence of cellmediated contraction, the leaflets lose their original 3D shape for a more planar geometry and shorten in the radial direction which results in reduced coaptation already at the moment of implantation. ${ }^{31}$

Recently we proposed a tissue-engineered fibrin-based heart valve based on a tubular leaflet design as an alternative to the classical design, abandoning the idea of mimicking the complex shape of the native leaflet to reproduce its function. ${ }^{23}$ Instead, a simple tubular construct is sutured in the aortic or pulmonary conduit by the SPACs technique so that it closes the conduit when exposed to diastolic backflow, without any rigid support or sewing ring to obtain superior hemodynamics (e.g., increased effective orifice area and lower transvalvular gradient) as clinically demonstrated for bioprostheses without any rigid frame. $^{2}$

In the present article we showed the feasibility of combining the tubular leaflet design with a transcatheter valve implantation technique. The tube-in-stent valves were obtained by suturing the tubular construct into self-expandable nitinol stents. The self-expandable stent was preferred to a balloon-expandable one to minimize the possible tissue damage due to surface friction during deployment. After a 3 week cultivation time, the valves were fully functional showing complete closure and unobstructed opening (Fig. 4 ), good cellularity, and aligned collagen deposition. The longitudinal orientation of the extracellular matrix (ECM) is the result of the applied conditioning protocol in agreement with results on the influence of the dynamic stimulation on tissue-engineered constructs from our and other groups. ${ }^{23,32-34}$ Elastin was not detected in the ECM of the tube-in-stent valves. The absence of an organized elastic network has been recognized as an issue in the cardiovascular tissue engineering field, ${ }^{35,36}$ as elastin is a fundamental protein that confers the capability of 
cardiovascular structures to recoil after stretching and, therefore, to function properly over time. While commonly not present in TEHVs during bioreactor conditioning, elastin has been detected after implantation as a result of in vivo remodeling although in lower amounts than in native HVs. ${ }^{17,20,37}$

A complete endothelial layer was obtained (Fig. 5). The valves underwent simulated delivery by being crimped, kept in the crimped conformation for $20 \mathrm{~min}$, and then deployed. This procedure did not influence the functionality of the leaflets and the opening area did not change. No damage of the ECM could be qualitatively and quantitatively assessed by immunohistology and collagen content analysis, respectively. A recently published study showed that crimping of glutaraldehyde-fixed bovine pericardial leaflets resulted in damage of the collagen fibers at the surface layers of the leaflets as detected by second harmonic generation microscopy. ${ }^{38}$ The damage was less substantial with increasing depth into the tissue and with decreasing crimping ratio. For a valve with an initial diameter of $25 \mathrm{~mm}$, the detectable damage was limited to the surface of the leaflets when the diameter in the crimped configuration was $6 \mathrm{~mm}$. In our case, the crimping was considerably less severe, as we simulated a (transapical) delivery of a $22 \mathrm{~mm}$ valve through a 24 French catheter (corresponding to $8 \mathrm{~mm}$ diameter). Furthermore, the authors did not perform any mechanical tests and could not, therefore, conclude whether the observed damage compromised the biomechanical strength of the leaflets. In our study, the tissue burst strength of uncrimped and crimped valves did not differ significantly. This result could also be explained by the time during which the valve was kept in the crimped configuration, which was meant as the time needed for delivery and, therefore, relatively short. Kiefer and colleagues ${ }^{39}$ studied the effect of the crimping time on the collagen structure in glutaraldehydefixed bovine pericardial valves. Crimping times of $1 \mathrm{~h}, 1$ day, and 1 month were tested and increasing damage of the collagen structure with increasing crimping time was assessed by Picrosirius red and transmission electron microscopy. However, the collagen damage did not correspond to accelerated calcification rates when the leaflets were implanted subcutaneously in the rat model for 12 weeks.

The mean pressure gradient and the regurgitation values as assessed in the flow-loop system were not significantly affected by the crimping procedure. The mean pressure gradients were comparable to those of commercial available TAVI systems ${ }^{40}$ and the regurgitation values were within the limits established by the International Standard Organization 5840:2012 for a $23 \mathrm{~mm}$ valve replacement (i.e., regurgitation of $20 \%)$.

In our study, damage to the endothelial layer could not be excluded. Although staining against CD31 might suggest the presence of a complete endothelium (Fig. 5AH, AK), a more detailed analysis by means of SEM could not exclude an influence on the crimping procedure on the continuity of the monolayer. Schmidt and colleagues reported incomplete endothelialization of the TEHV after crimping likely due to surface friction, however, no thromboembolic event was observed in vivo in the sheep model. ${ }^{5}$ Current preclinical investigations performed in our group on a tissue-engineered covered stent for percutaneous treatment of occluded peripheral vessels ${ }^{41}$ confirmed that the crimping procedure for the catheter-based delivery might result in small lesions of the endothelial layer which, although, does not lead to any in vivo complications (unpublished data). The clinical relevance of these results, however, cannot be straightforwardly transferred to the human case because, differently from humans, the sheep has the capability to spontaneously endothelialize implants. ${ }^{42,43}$ Therefore, an animal model which does not possess this capability (e.g., pig) will be used in future preclinical tests. Furthermore, the effect of an anticoagulant therapy, as normally administered postimplantation, on the healing capabilities and timing of the endothelium should also be investigated. Following the general tendency to reduce the catheter size,${ }^{26}$ we crimped the valves to $8 \mathrm{~mm}$, however, a possible way to minimize eventual damage to the endothelium could be crimping to a lower extend. Newly developed commercial TAVI models to be placed transapically are designed for 28-32 French delivery catheters (approximately corresponding to a 9$11 \mathrm{~mm}$ diameter) even for $23 \mathrm{~mm}$ valves. ${ }^{26,44}$ Even when the crimping procedure is proven to be safe, the functionality of the endothelium once in the corporeal circulation still needs to be carefully evaluated. An alternative solution could be the in situ endothelialization by capturing circulating endothelial progenitor cells from the bloodstream. ${ }^{45}$ Such method would eliminate the need for invasive and timeconsuming cell isolation and cultivation with the associated risk of contamination. ${ }^{46}$

In the tube-in-stent concept, there is no tissue-engineered vascular wall covering the nitinol stent. This implies that the blood flow to the sinuses of Valsalva is maintained, which means physiological hemodynamics and, in the case of aortic implantation, also proper perfusion of the coronary arteries. In the tube-in-stent proof-of-principle, we used a warp knitted mesh as co-scaffold. While we previously demonstrated that the tubular conduit could be realized entirely in fibrin as matrix, ${ }^{23}$ we believe the presence of a textile structure is crucial to confer mechanical stability to the construct. Particularly for the systemic circulation, TEHVs have proven to be mechanically inadequate and all preclinical studies (including the ones with minimally invasive technology) with a relevant duration ( $\geq 4$ weeks) have been realized with implantations in the low-pressure pulmonary position. We have shown that tissue-engineered small-caliber vascular grafts based on a combination of fibrin and a warp knitted mesh were successfully implanted in the high-pressure arterial circulation of the sheep and remained patent for the whole duration of the study (6 months). ${ }^{47}$ This holds hope for a textile-reinforced TEHV able to withstand the systemic circulation. Also the fact that the tube-in-stent's functionality was not hindered due to cell-mediated tissue contraction during the in vitro fabrication process is an encouraging aspect.

The results presented in this article show the potential of combining the tubular leaflet design with transcatheter technologies, however, they are still preliminary and further investigation is ongoing, including durability assessment, optimization of the conditioning protocol, and of the stent design.

In this study, a simple tubular stent was used for the proof-of-principle, however, it is clear that the stent is of critical importance for the valves' performance. Clinical experience with TAVI systems has shown the need to 
optimize the stent and the delivery system to avoid atrioventricular block and damage of the mitral valve during implantation, to enable repositioning facilitating proper valve placement, and to minimize paravalvular leakage, for example with the use of a polymeric or bioprosthetic skirt/ cuff in the lower part of the stent. ${ }^{44}$

This study presents the proof-of-principle of a new transcatheter TEHV based on a tubular structure, combining the advantages of minimally invasive technology and tissue engineering, that is, capability to remodel, self-repair, and physiological hemocompatibility. Although TAVI is currently restricted to inoperable and high-risk patients with severe, symptomatic aortic stenosis, upcoming devices promise to improve the performance of recent TAVI systems (e.g., by addressing periprosthetic regurgitation and conduction disturbance), so that younger and healthier individuals might benefit from this technology in the near future, ${ }^{44,48}$ making the advantage of a living tissue with regeneration potential of crucial relevance for the long-term performance of the system.

\section{Study limitations}

The potential advantage of the tubular design to overcome the functional limitations (i.e., valvular insufficiency) due to the cell-mediated tissue contraction reported for TEHVs reproducing the native leaflet geometry remains to be tested in vivo. Also the strategy of engineering an endothelium in vitro before implantation has to be evaluated by following the fate of the endothelial cells when exposed to the physiological environment of an appropriate animal model.

\section{Acknowledgments}

This research was funded by the People Program (Marie Curie Actions) of the European Union's Seventh Framework Program FP7/2007-2013/under REA grant agreement $n^{\circ} 317512$. The authors would like to thank the Admedes Schuessler $\mathrm{GmbH}$ for providing the stents used in this study.

\section{Disclosure Statement}

No competing financial interests exist.

\section{References}

1. Iung, B., and Vahanian, A. Epidemiology of valvular heart disease in the adult. Nat Rev Cardiol 8, 162, 2011.

2. Padala, M., Keeling, W.B., Guyton, R.A., and Thourani, V.H. Innovations in therapies for heart valve disease. Circ J 75, 1028, 2011.

3. Pibarot, P., and Dumesnil, J.G. Prosthetic heart valves: selection of the optimal prosthesis and long-term management. Circulation 119, 1034, 2009.

4. Llames, S., Garcia, E., Otero Hernandez, J., and Meana, A. Tissue bioengineering and artificial organs. Adv Exp Med Biol 741, 314, 2012.

5. Schmidt, D., Dijkman, P.E., Driessen-Mol, A., Stenger, R., Mariani, C., Puolakka, A., Rissanen, M., Deichmann, T., Odermatt, B., Weber, B., Emmert, M.Y., Zund, G., Baaijens, F.P., and Hoerstrup, S.P. Minimally-invasive implantation of living tissue engineered heart valves: a comprehensive approach from autologous vascular cells to stem cells. J Am Coll Cardiol 56, 510, 2010.

6. Zajarias, A., and Cribier, A.G. Outcomes and safety of percutaneous aortic valve replacement. J Am Coll Cardiol 53, 1829, 2009.

7. Makkar, R.R., Fontana, G.P., Jilaihawi, H., Kapadia, S., Pichard, A.D., Douglas, P.S., Thourani, V.H., Babaliaros, V.C., Webb, J.G., Herrmann, H.C., Bavaria, J.E., Kodali, S., Brown, D.L., Bowers, B., Dewey, T.M., Svensson, L.G., Tuzcu, M., Moses, J.W., Williams, M.R., Siegel, R.J., Akin, J.J., Anderson, W.N., Pocock, S., Smith, C.R., Leon, M.B., and Investigators, P.T. Transcatheter aortic-valve replacement for inoperable severe aortic stenosis. N Engl J Med 366, 1696, 2012.

8. Butcher, J.T., Mahler, G.J., and Hockaday, L.A. Aortic valve disease and treatment: the need for naturally engineered solutions. Adv Drug Deliv Rev 63, 242, 2011.

9. Hoerstrup, S.P., Sodian, R., Daebritz, S., Wang, J., Bacha, E.A., Martin, D.P., Moran, A.M., Guleserian, K.J., Sperling, J.S., Kaushal, S., Vacanti, J.P., Schoen, F.J., and Mayer, J.E., Jr. Functional living trileaflet heart valves grown in vitro. Circulation 102, III44, 2000.

10. Jockenhoevel, S., Chalabi, K., Sachweh, J.S., Groesdonk, H.V., Demircan, L., Grossmann, M., Zund, G., and Messmer, B.J. Tissue engineering: complete autologous valve conduit-a new moulding technique. Thorac Cardiovasc Surg 49, 287, 2001.

11. Klopsch, C., Gabel, R., Kaminski, A., Mark, P., Wang, W., Toelk, A., Delyagina, E., Kleiner, G., Koch, L., Chichkov, B., Mela, P., Jockenhoevel, S., Ma, N., and Steinhoff, G. Spray- and laser-assisted biomaterial processing for fast and efficient autologous cell-plus-matrix tissue engineering. J Tissue Eng Regen Med 2012 [Epub ahead of print]; DOI: $10.1002 /$ term. 1657 .

12. Mol, A., Rutten, M.C., Driessen, N.J., Bouten, C.V., Zund, G., Baaijens, F.P., and Hoerstrup, S.P. Autologous human tissue-engineered heart valves: prospects for systemic application. Circulation 114, I152, 2006.

13. Robinson, P.S., Johnson, S.L., Evans, M.C., Barocas, V.H., and Tranquillo, R.T. Functional tissue-engineered valves from cell-remodeled fibrin with commissural alignment of cell-produced collagen. Tissue Eng Part A 14, 83, 2008.

14. Shinoka, T., Breuer, C.K., Tanel, R.E., Zund, G., Miura, T., Ma, P.X., Langer, R., Vacanti, J.P., and Mayer, J.E., Jr. Tissue engineering heart valves: valve leaflet replacement study in a lamb model. Ann Thorac Surg 60, S513, 1995.

15. Sodian, R., Sperling, J.S., Martin, D.P., Egozy, A., Stock, U., Mayer, J.E., Jr., and Vacanti, J.P. Fabrication of a trileaflet heart valve scaffold from a polyhydroxyalkanoate biopolyester for use in tissue engineering. Tissue Eng 6, $183,2000$.

16. Sutherland, F.W., Perry, T.E., Yu, Y., Sherwood, M.C., Rabkin, E., Masuda, Y., Garcia, G.A., McLellan, D.L., Engelmayr, G.C., Jr., Sacks, M.S., Schoen, F.J., and Mayer, J.E., Jr. From stem cells to viable autologous semilunar heart valve. Circulation 111, 2783, 2005.

17. Flanagan, T.C., Sachweh, J.S., Frese, J., Schnoring, H., Gronloh, N., Koch, S., Tolba, R.H., Schmitz-Rode, T., and Jockenhoevel, S. In vivo remodeling and structural characterization of fibrin-based tissue-engineered heart valves in the adult sheep model. Tissue Eng Part A 15, 2965, 2009. 
18. Gottlieb, D., Kunal, T., Emani, S., Aikawa, E., Brown, D.W., Powell, A.J., Nedder, A., Engelmayr, G.C., Jr., Melero-Martin, J.M., Sacks, M.S., and Mayer, J.E., Jr. In vivo monitoring of function of autologous engineered pulmonary valve. J Thorac Cardiovasc Surg 139, 723, 2010.

19. Shinoka, T., Shum-Tim, D., Ma, P.X., Tanel, R.E., Langer, R., Vacanti, J.P., and Mayer, J.E., Jr. Tissue-engineered heart valve leaflets: does cell origin affect outcome? Circulation 96, II, 1997.

20. Syedain, Z.H., Lahti, M.T., Johnson, S.L., Robinson, P.S., Ruth, G.R., Bianco, R.W., and Tranquillo, R.T. Implantation of a tissue-engineered heart valve from human fibroblasts exhibiting short term function in the sheep pulmonary artery. Cardiovasc Eng Tech 2, 101, 2011.

21. Weber, B., Dijkman, P.E., Scherman, J., Sanders, B., Emmert, M.Y., Grunenfelder, J., Verbeek, R., Bracher, M., Black, M., Franz, T., Kortsmit, J., Modregger, P., Peter, S., Stampanoni, M., Robert, J., Kehl, D., van Doeselaar, M., Schweiger, M., Brokopp, C.E., Walchli, T., Falk, V., Zilla, P., Driessen-Mol, A., Baaijens, F.P., and Hoerstrup, S.P. Off-the-shelf human decellularized tissue-engineered heart valves in a non-human primate model. Biomaterials 34, 7269, 2013.

22. Weber, B., Scherman, J., Emmert, M.Y., Gruenenfelder, J., Verbeek, R., Bracher, M., Black, M., Kortsmit, J., Franz, T., Schoenauer, R., Baumgartner, L., Brokopp, C., Agarkova, I., Wolint, P., Zund, G., Falk, V., Zilla, P., and Hoerstrup, S.P. Injectable living marrow stromal cell-based autologous tissue engineered heart valves: first experiences with a one-step intervention in primates. Eur Heart J 32, 2830, 2011.

23. Weber, M., Heta, E., Moreira, R., Gesche, V.N., Schermer, T., Frese, J., Jockenhoevel, S., and Mela, P. Tissue-engineered fibrin-based heart valve with a tubular leaflet design. Tissue Eng Part C Methods 20, 265, 2014.

24. Goetz, W.A., Lim, H.S., Lansac, E., Weber, P.A., and Duran, C.M. A temporarily stented, autologous pericardial aortic valve prosthesis. J Heart Valve Dis 11, 696, 2002.

25. Reddy, G.K., and Enwemeka, C.S. A simplified method for the analysis of hydroxyproline in biological tissues. Clin Biochem 29, 225, 1996.

26. Rodes-Cabau, J. Transcatheter aortic valve implantation: current and future approaches. Nat Rev Cardiol 9, 15, 2012.

27. Hahn, R.T., Pibarot, P., Stewart, W.J., Weissman, N.J., Gopalakrishnan, D., Keane, M.G., Anwaruddin, S., Wang, Z., Bilsker, M., Lindman, B.R., Herrmann, H.C., Kodali, S.K., Makkar, R., Thourani, V.H., Svensson, L.G., Akin, J.J., Anderson, W.N., Leon, M.B., and Douglas, P.S. Comparison of transcatheter and surgical aortic valve replacement in severe aortic stenosis: a longitudinal study of echocardiography parameters in cohort A of the PARTNER trial (placement of aortic transcatheter valves). J Am Coll Cardiol 61, 2514, 2013.

28. Smith, C.R., Leon, M.B., Mack, M.J., Miller, D.C., Moses, J.W., Svensson, L.G., Tuzcu, E.M., Webb, J.G., Fontana, G.P., Makkar, R.R., Williams, M., Dewey, T., Kapadia, S., Babaliaros, V., Thourani, V.H., Corso, P., Pichard, A.D., Bavaria, J.E., Herrmann, H.C., Akin, J.J., Anderson, W.N., Wang, D., Pocock, S.J., and Investigators, P.T. Transcatheter versus surgical aortic-valve replacement in high-risk patients. N Engl J Med 364, 2187, 2011.
29. Eggebrecht, H., Schafer, U., Treede, H., Boekstegers, P., Babin-Ebell, J., Ferrari, M., Mollmann, H., Baumgartner, H., Carrel, T., Kahlert, P., Lange, P., Walther, T., Erbel, R., Mehta, R.H., and Thielmann, M. Valve-in-valve transcatheter aortic valve implantation for degenerated bioprosthetic heart valves. JACC Cardiovasc Interv 4, 1218, 2011.

30. Dijkman, P.E., Driessen-Mol, A., Frese, L., Hoerstrup, S.P., and Baaijens, F.P. Decellularized homologous tissueengineered heart valves as off-the-shelf alternatives to xeno- and homografts. Biomaterials 33, 4545, 2012.

31. Emmert, M.Y., Weber, B., Falk, V., and Hoerstrup, S.P. Transcatheter tissue engineered heart valves. Expert Rev Med Devices 11, 15, 2014.

32. Flanagan, T.C., Cornelissen, C., Koch, S., Tschoeke, B., Sachweh, J.S., Schmitz-Rode, T., and Jockenhoevel, S. The in vitro development of autologous fibrin-based tissueengineered heart valves through optimised dynamic conditioning. Biomaterials 28, 3388, 2007.

33. Rubbens, M.P., Mol, A., Boerboom, R.A., Bank, R.A., Baaijens, F.P., and Bouten, C.V. Intermittent straining accelerates the development of tissue properties in engineered heart valve tissue. Tissue Eng Part A 15, 999, 2009.

34. Syedain, Z.H., Weinberg, J.S., and Tranquillo, R.T. Cyclic distension of fibrin-based tissue constructs: evidence of adaptation during growth of engineered connective tissue. Proc Natl Acad Sci U S A 105, 6537, 2008.

35. Patel, A., Fine, B., Sandig, M., and Mequanint, K. Elastin biosynthesis: The missing link in tissue-engineered blood vessels. Cardiovasc Res 71, 40, 2006.

36. Mol, A., Smits, A.I., Bouten, C.V., and Baaijens, F.P. Tissue engineering of heart valves: advances and current challenges. Expert Rev Med Devices 6, 259, 2009.

37. Driessen-Mol, A., Emmert, M.Y., Dijkman, P.E., Frese, L., Sanders, B., Weber, B., Cesarovic, N., Sidler, M., Leenders, J., Jenni, R., Grunenfelder, J., Falk, V., Baaijens, F.P., and Hoerstrup, S.P. Transcatheter implantation of homologous "off-the-shelf" tissue-engineered heart valves with self-repair capacity: long-term functionality and rapid in vivo remodeling in sheep. J Am Coll Cardiol 63, 1320, 2014.

38. Alavi, S.H., Groves, E.M., and Kheradvar, A. The effects of transcatheter valve crimping on pericardial leaflets. Ann Thorac Surg 97, 1260, 2014.

39. Kiefer, P., Gruenwald, F., Kempfert, J., Aupperle, H., Seeburger, J., Mohr, F.W., and Walther, T. Crimping may affect the durability of transcatheter valves: an experimental analysis. Ann Thorac Surg 92, 155, 2011.

40. Spethmann, S., Dreger, H., Schattke, S., Baldenhofer, G., Saghabalyan, D., Stangl, V., Laule, M., Baumann, G., Stangl, K., and Knebel, F. Doppler haemodynamics and effective orifice areas of Edwards SAPIEN and CoreValve transcatheter aortic valves. Eur Heart J Cardiovasc Imaging 13, 690, 2012.

41. Weinandy, S., Rongen, L., Schreiber, F., Cornelissen, C., Flanagan, T.C., Mahnken, A., Gries, T., Schmitz-Rode, T., and Jockenhoevel, S. The BioStent: novel concept for a viable stent structure. Tissue Eng Part A 18, 1818, 2012.

42. Grabenwoger, M., Fitzal, F., Sider, J., Cseko, C., Bergmeister, H., Schima, H., Husinsky, W., Bock, P., and Wolner, E. Endothelialization of biosynthetic vascular prostheses after laser perforation. Ann Thorac Surg 66, S110, 1998. 
43. Hoffman, D., Gong, G., Liao, K., Macaluso, F., Nikolic, S.D., and Frater, R.W. Spontaneous host endothelial growth on bioprostheses. Influence of fixation. Circulation 86, II75, 1992.

44. Sinning, J.M., Werner, N., Nickenig, G., and Grube, E. Next-generation transcatheter heart valves: current trials in Europe and the USA. Methodist Debakey Cardiovasc J 8, 9 , 2012.

45. Schleicher, M., Wendel, H.P., Fritze, O., and Stock, U.A. In vivo tissue engineering of heart valves: evolution of a novel concept. Regen Med 4, 613, 2009.

46. Liu, T., Liu, S., Zhang, K., Chen, J., and Huang, N. Endothelialization of implanted cardiovascular biomaterial surfaces: the development from in vitro to in vivo. J Biomed Mater Res A 102, 3754, 2014.

47. Koch, S., Flanagan, T.C., Sachweh, J.S., Tanios, F., Schnoering, H., Deichmann, T., Ella, V., Kellomaki, M., Gronloh, N., Gries, T., Tolba, R., Schmitz-Rode, T., and Jockenhoevel, S. Fibrin-polylactide-based tissue-engineered vascular graft in the arterial circulation. Biomaterials 31, 4731, 2010.

48. Tamburino, C., Barbanti, M., Capodanno, D., Sarkar, K., Cammalleri, V., Scarabelli, M., Mule, M., Imme, S., Aruta, P., and Ussia, G.P. Early- and mid-term outcomes of transcatheter aortic valve implantation in patients with logistic EuroSCORE less than 20\%: a comparative analysis between different risk strata. Catheter Cardiovasc Interv 79, 132, 2012.
Address correspondence to:

Petra Mela, PhD

Department of Tissue Engineering and Textile Implants Institute of Applied Medical Engineering

Helmholtz Institute

RWTH Aachen University

Pauwelsstr. 20

Aachen 52074

Germany

E-mail: mela@hia.rwth-aachen.de

Stefan Jockenhoevel, MD

Department of Tissue Engineering and Textile Implants Institute of Applied Medical Engineering

Helmholtz Institute

RWTH Aachen University

Pauwelsstr. 20

Aachen 52074

Germany

E-mail: jockenhoevel@hia.rwth-aachen.de

Received: April 16, 2014

Accepted: October 21, 2014

Online Publication Date: December 18, 2014 